\section{ANALYSIS OF THE FLAME FRONT GEOMETRY RESPECT TO THE NOX FORMATION}

\author{
ANDRII KULIKOV, MIROSLAV RIMAR, MARCEL FEDAK, \\ OLHA KULIKOVA
}

Technical University of Kosice, Faculty of Manufacturing Technologies with a seat in Presov, Department of Process Technique, Presov, Slovak Republic

DOI: 10.17973/MMSJ.2019_12_2019024

e-mail: miroslav.rimar@tuke.sk

Natural gas is one of the cleanest organic fuels, nevertheless it produces pollutants in combustion process. The major pollutants of the combustion in the atmosphere are carbon monoxide $\mathrm{CO}$, nitrogen oxides $\mathrm{NO}, \mathrm{NO} 2$, sulphur dioxide $\mathrm{SO} 2$ and hydrocarbons. Current article deals with the problematic of the high NOx formation rates under the high power operation. The object under research was middle pressure natural gas boiler with the power of $35 \mathrm{MW}$. The reason of high NOx formation rate was eliminated due to primary deNOx methods.

KEYWORDS

Boiler, burner, heating, natural gas, ANSYS

\section{INTRODUCTION}

Natural gas is the most common fuel nowadays [Rimar 2014]. The process of burning gas is a chemical reaction in which natural gas interacts with oxygen, which is contained in the air [Smeringai 2015]. In the gaseous fuel there is a combustible and non-combustible parts [Smeringai 2014].

To ensure high-quality gas combustion, it is necessary to supply sufficient air to the combustion zone and achieve good gas mixing with air [Varga 2015]. The optimum ratio is approximately 1:10 [Rimar 2013]. Such significant ration is a results high N2 concentration in the air [Tolias 2018].

The major pollutants of the combustion in the atmosphere are carbon monoxide $\mathrm{CO}$, nitrogen oxides $\mathrm{NO}, \mathrm{NO} 2$, sulphur dioxide SO2 and hydrocarbons [Panda 2014]. The most toxic emissions are nitrogen oxides [Dzurnak 2015]. The largest component of natural gas is methane, a compound with one carbon atom and four hydrogen atoms ( $\mathrm{CH} 4)$. Natural gas also contains smaller amounts of natural gas liquids (NGL; which are also hydrocarbon gas liquids), and nonhydrocarbon gases, such as carbon dioxide and water vapor.

The research subject of the current work is overlay of the flame fronts in the combustion chamber in the two burners system.

\section{MATERIALS AND METHODS}

\subsection{Equipment description}

The subject under research is the $35 \mathrm{MW}$ boiler with two equal 17.6 MW burner installed in the horizontal axis of the combustion chamber.
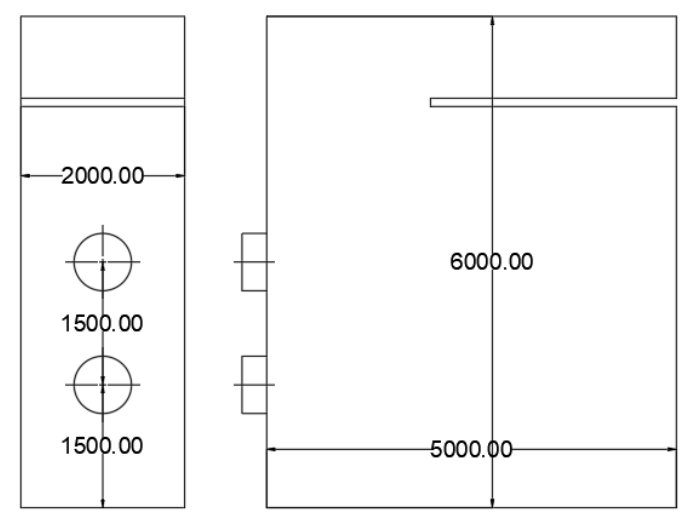

Figure 1. Model of boiler

The technical parameters of the boiler and burners are at the table 1.

Table 1. Technical parameters of the boiler

\begin{tabular}{|c|c|}
\hline Boiler type & Middle pressured \\
\hline Manufacturer & ČKD Tatra Kolín \\
\hline Highest overpressure & $4.5 \mathrm{MPa}$ \\
\hline Nominal overpressure & $3.8 \mathrm{MPa}$ \\
\hline Designed overpressure & $4.0 \mathrm{MPa}$ \\
\hline Hearth type & over pressure \\
\hline Nominal steam output & 40 t.h-1 \\
\hline Efficiency at nominal parameters & $90 \%$ \\
\hline Fuel & NG/HFO \\
\hline Minimum output & 10 t.h-1 \\
\hline Nominal steam temperature & $720 \mathrm{~K}$ \\
\hline Nominal feed water temperature & $420 \mathrm{~K}$ \\
\hline Burner type & VKH-17.8-1P \\
\hline Manufacturer & HT a.s. \\
\hline Nominal thermal output & $17.6 \mathrm{MW}$ \\
\hline Gaseous fuel NG consumption & 1750 m3.h-1 \\
\hline Nominal pressure of gaseous fuel - NG & $50 \mathrm{kPa}$ \\
\hline Liquid fuel HHO consumption & 1.6 t.h-1 \\
\hline Nominal pressure of liquid $\mathrm{HHO}$ fuel & $3.2 \mathrm{MPa}$ \\
\hline Number of air fans & 1 \\
\hline Output of air fans & $2 \times 12 \mathrm{~m} 3 . \mathrm{s}-1$ \\
\hline Output of smoke fan & 37.6 m3.s-1 \\
\hline Designed under pressure in the hearth & $20 \mathrm{~Pa}$ \\
\hline Combustion air temperature & $475 \mathrm{~K}$ \\
\hline Number of burners & 2 \\
\hline
\end{tabular}


Burner type

Gaseous fuel consumption

Burner regulating range at gaseous fuel

Gas overpressure before the burner

Combustion air pressure
VKH $17.61 \mathrm{P} \frac{\partial}{\partial t}(\rho \varepsilon)+\frac{\partial}{\partial x_{j}}\left(\rho \varepsilon u_{j}\right)=\frac{\partial}{\partial x_{j}}\left[\left(\mu+\frac{\mu_{t}}{\sigma_{\varepsilon}}\right) \frac{\partial \varepsilon}{\partial x_{j}}\right]+\rho C_{1} S_{\varepsilon}-$

$1820 \mathrm{Nm} 3 . \mathrm{h}-1 \rho C_{2} \frac{\varepsilon^{2}}{k+\sqrt{\varepsilon v}}+C_{1 \varepsilon} \frac{\varepsilon}{k} C_{3 \varepsilon} G_{b}+S_{\varepsilon}$

$1: 5$

$100 \mathrm{kPa}$

$1600 \mathrm{~Pa} \quad C_{1}=\max \left[0.43, \frac{\eta}{\eta+5}\right], \eta=S \frac{k}{\varepsilon}, S=\sqrt{2 S_{i j} S_{i j}}$

\subsection{Model creation}

The simulations of the two burners combustion chamber were made in ANSYS Fluent 19.0. The geometry of the model was made in ANSYS DesignModeller according to the technical and geometry parameters of the burners and boiler. The redrawn geometry was simplified to decrease the numbers of the nodes and elements in the mesh to reduce calculation time of the simulation [Krenicky 2010]. Nevertheless, any changes in the geometry does not influence thermodynamics or chemistry processes in the boiler [Jandacka 2015].

\subsection{The mesh}

The mesh was developed in ANSYS for the CFD Fluent solver with proximity and curvature advanced size function [Deshpande 2017]. Owing to the differences of the input and output dimension proximity minimum size was selected as $1.6 \mathrm{~mm}$ while the maximum was $500 \mathrm{~mm}$ [Song 2018]. The growth rate parameter was applied at 1.30 [Saini 2018]. The quality of mesh was next: $75 \%$ of all elements had orthogonal quality more than 0.78 while the lowest rate was 0.41 at less than $1 \%$ of the elements, the worst skewness of the grid was 0.65 at less than $8 \%$ of the elements [Garre 2018]. According to that parameters the quality of mesh was appropriate for the simulation without dependences on the calculation results [ANSYS 2019]. Total number of the elements in the model mesh is 10118163 Example of the generated mesh is in the figure 2.

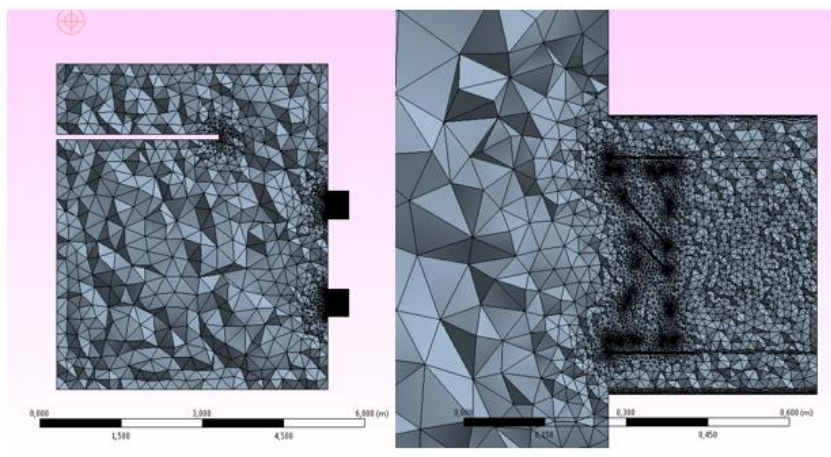

Figure 2. Generated mesh

When defining the turbulence model, verification simulations were implemented using integrated modules RANS and then LES. The results of the boiler simulations showed that from the point of view of the calculation stability, the realizable k-epsilon model, which was also applied for the simulations, was the best.

The solved transport equation for the realizable k-epsilon model has the following form:

$\frac{\partial}{\partial t}(\rho k)+\frac{\partial}{\partial x_{j}}\left(\rho k u_{j}\right)=\frac{\partial}{\partial x_{j}}\left[\left(\mu+\frac{\mu_{t}}{\sigma_{k}}\right) \frac{\partial k}{\partial x_{j}}\right]+G_{k}+G_{b}-\rho \varepsilon-$

$Y_{M}+S_{k}$

and
- In these equations, $G_{k}$ represents the generation of kinetic energy of turbulence due to mean velocity gradients.

- $G_{b}$ is the generation of kinetic energy by turbulence considering buoyancy.

- $\mathrm{Y}_{\mathrm{M}}$ represents a manifestation of fluctuating dilation in compressible turbulence to the overall scattering rate.

- $\mathrm{C}_{1 \varepsilon}, \mathrm{C}_{3 \varepsilon}$, and $\mathrm{C}_{2}$ are constants.

- $\sigma \mathrm{k}$ and $\sigma \varepsilon$ are turbulent Prandtl numbers for $\mathrm{k}$ and $\mathrm{e}$.

- $\mathrm{S}_{\mathrm{k}}$ and $\mathrm{S}_{\varepsilon}$ are user-defined source formulas.

The transport equation PDF is derived from the Navier-Stokes equation as (Smeringai 2014):

$\frac{\partial}{\partial t}(\rho P)+\frac{\partial}{\partial x_{i}}\left(\rho u_{i} P\right)+\frac{\partial}{\partial \psi_{i}}\left(\rho S_{k} P\right)=-\frac{\partial}{\partial x_{i}}\left[\rho\left\langle u_{i}^{\prime \prime} \mid \psi\right\rangle P\right]+$

$\frac{\partial}{\partial \psi_{i}}\left[\rho\left\langle\frac{1}{\rho} \frac{\partial J_{i, k}}{\partial x_{i}} \mid \psi\right\rangle P\right]$

Where

$\mathrm{P}$ - common composition of PDF and Favre,

$\rho$ - average liquid density,

$\mathrm{u}_{\mathrm{i}}-$ Favre velocity vector,

$S_{k}-$ rate of reaction of k elements,

$\psi$-space composition vector,

$u_{i "}-$ vector of fluid velocity fluctuation,

$\mathrm{J}_{\mathrm{ik}}-$ molecular diffusion flow vector.

Notation $\langle\ldots .$.$\rangle indicates expectations, and \langle A \mid B\rangle$ is the conditional probability of event $A$ when event $B$ occurs.

The turbulent scalar flow is not closed and is modelled by the assumption of diffusion gradient transition (Song 2012):

$-\frac{\partial}{\partial x_{i}}\left[\rho\left\langle u_{i}^{\prime \prime} \mid \psi\right\rangle P\right]=\frac{\partial}{\partial x_{i}}\left(\frac{\rho \mu_{t}}{S c_{t}} \frac{\partial P}{\partial x_{i}}\right)$

Where

$\mu \mathrm{t}$ is turbulent viscosity,

$\mathrm{S}_{\mathrm{ct}}$ is Schmidt number.

The Turbulence model specifies $\mu$ t for the composition of PDF simulation.

The inlet boundary conditions for turbulence parameters were chosen through determination of turbulent intensity what depend on the Reynolds numbers.

Better analysis of chosen model was made in earlier studies [Rimar 2016]. The convergence of calculation was archived approximately after 9500 iterations, when the parameters of continuity, velocity, energy, temperature, radiation, NOx and other reduced min. under $10^{-5}$ [ANSYS 2019]. 


\section{SIMULATION}

To understand the thermos mechanical processes inside the boiler simulation of the non-premixed combustion was made. All input physical parameters were chosen according to the normal operation conditions of the boiler and the burners.

The PDF (Probability density function) settings were made according to the air fan normal operation conditions and natural gas composition according to the SPP (Slovak gas industry) report [Dobakova 2018]. The natural gas composition is at the table 2 .

Table 2. Natural gas composition, (\%)

\begin{tabular}{cccccc}
\hline Methane & Ethan & Propane & Bethan & Nitrogen & Other \\
\hline 95.3658 & 2.4716 & 0.6724 & 0.1007 & 0.8131 & 0.5764 \\
\hline
\end{tabular}

Results of the reference simulation are at the figure 3 (temperature contours), figure 4 (NO mass fraction).

At the upper part of the figure 3 are shown temperature contours in $\mathrm{XY}$ axis, at the lower part of the figure 3 are shown temperature contours in $Z X$ axis. The maximum flame temperature in the combustion chamber is $2229 \mathrm{~K}$, while the volume average temperature is $1900 \mathrm{~K}$.
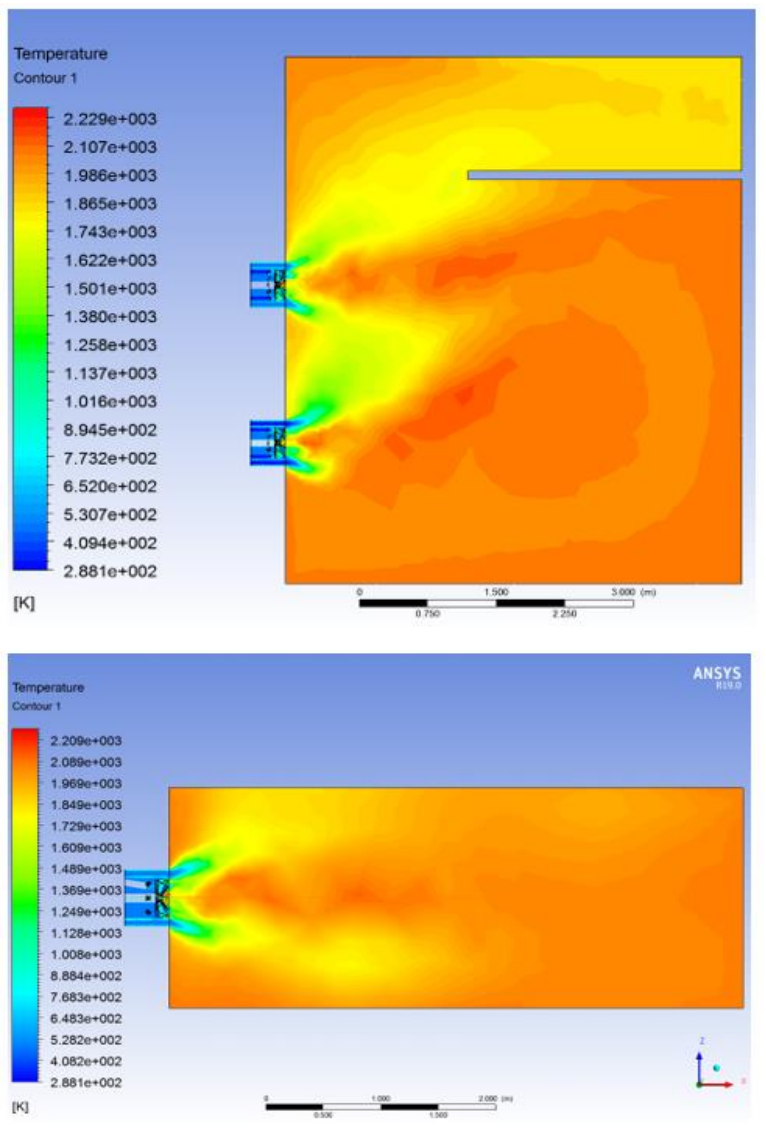

Figure 3. Simulation results. Temperature contours

According to the Arhenius formulation of the thermal nitrogen oxides formation the critical internal temperature is $1500 \mathrm{~K}$. Above this temperature NOx production raise exponentially.

Nevertheless, the reduction of the internal temperature under critical will lead to the reduction of the power and then production efficiency of the boiler.
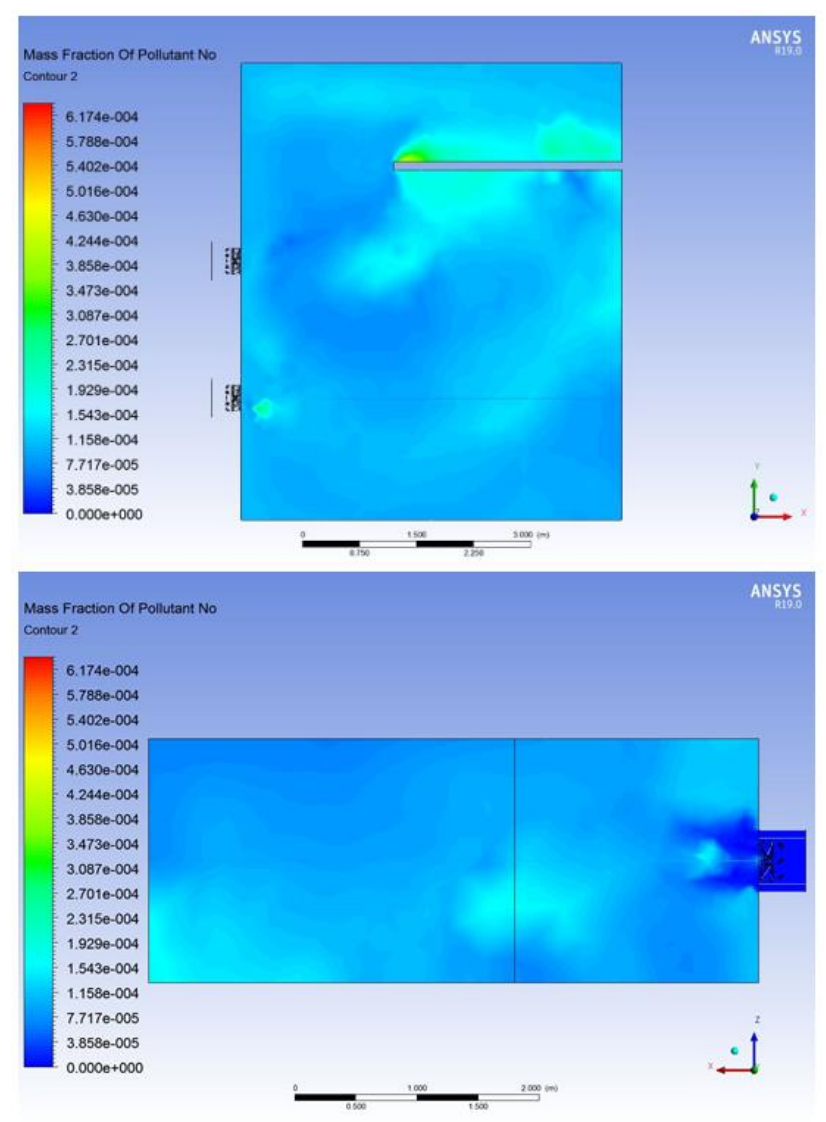

Figure 4. Simulation results. NOx Mass Fraction

Figure 4 represents mass fraction of the NO. Maximum concentration of the NOx in the boiler is $193 \mathrm{mg} / \mathrm{m}^{3}$. The average concentration inside the combustion chamber is $124 \mathrm{mg} / \mathrm{m}^{3}$, concentration at the exhauster is $138 \mathrm{mg} / \mathrm{m}^{3}$. From the EU legislative the maximum possible NOx exhausting for such thermal equipment is $250 \mathrm{mg} / \mathrm{m}^{3}$ (taking to account year of reconstruction and burners type).

According to the results the most of the NO is produced at the end of the flame, close to the wall and at the area at the end of flame fronts. As it is represented in the figure 4 the thermal NOx are the main source of the pollutants. According to the simulation results approximately $70 \%$ of NOx inside the combustion chamber were produced via thermal NOx production scheme, while via the rapid and fuel were produced $25 \%$ and $5 \%$ accordantly.

The main problem of the high NOx production is the flames conjunction in vertical axis. Such conjunction lead to the increasing of the temperature at the end of the flame fronts. To disconnect the flames was proposed to use primary deNOx methods. As an advantages of the primary methods are minimum impact to the power of the boiler and relatively small investments. As the most appropriate were chosen next steps:

- Change the natural gas distribution between the burners - increase the power of the upper burner by $3 \%$ and decrease the power of the lower burner by $3 \%$

- Change the combustion air ratio at the lower burner the basic ratio was $70 \%$ of primary to $30 \%$ of secondary air, the new ration $65 \%$ of primary air to $35 \%$ of secondary air. 
The results of the simulation with the new combustion parameters are at the figure 5 (temperature contours), figure 6 (NO mass fraction).
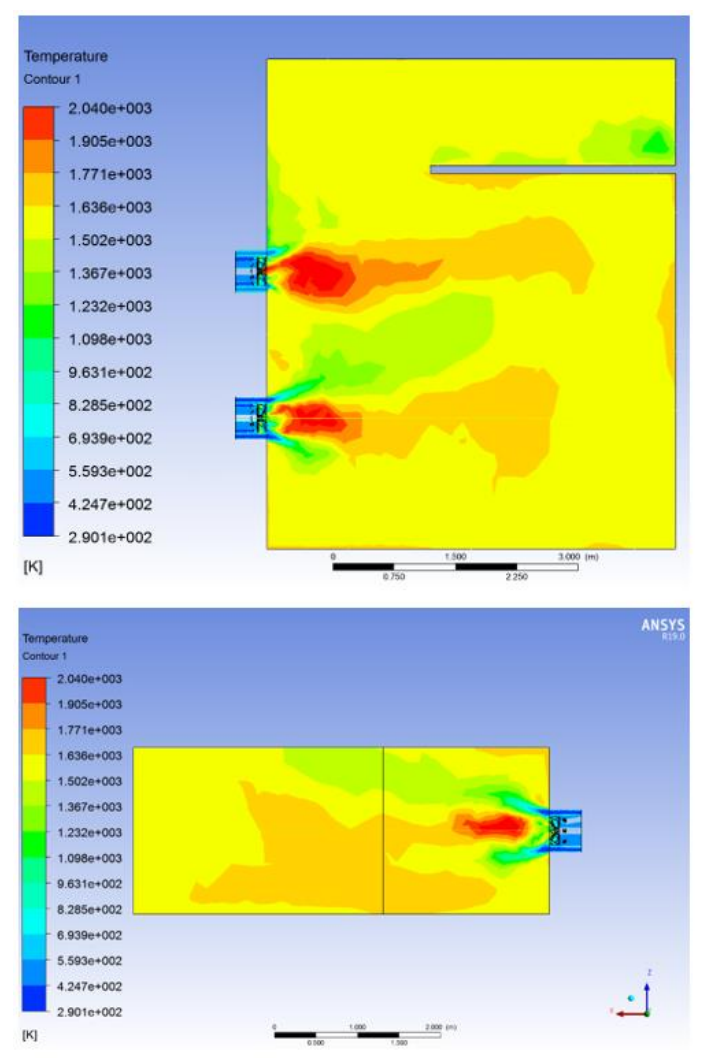

Figure 5. Simulation results. Temperature contours

At the upper part of the figure 5 are shown temperature contours in $\mathrm{XY}$ axis, at the lower part of the figure 3 are shown temperature contours in ZX axis. The maximum flame temperature in the combustion chamber is $2041 \mathrm{~K}$, while the volume average temperature is approximately $1800 \mathrm{~K}$.
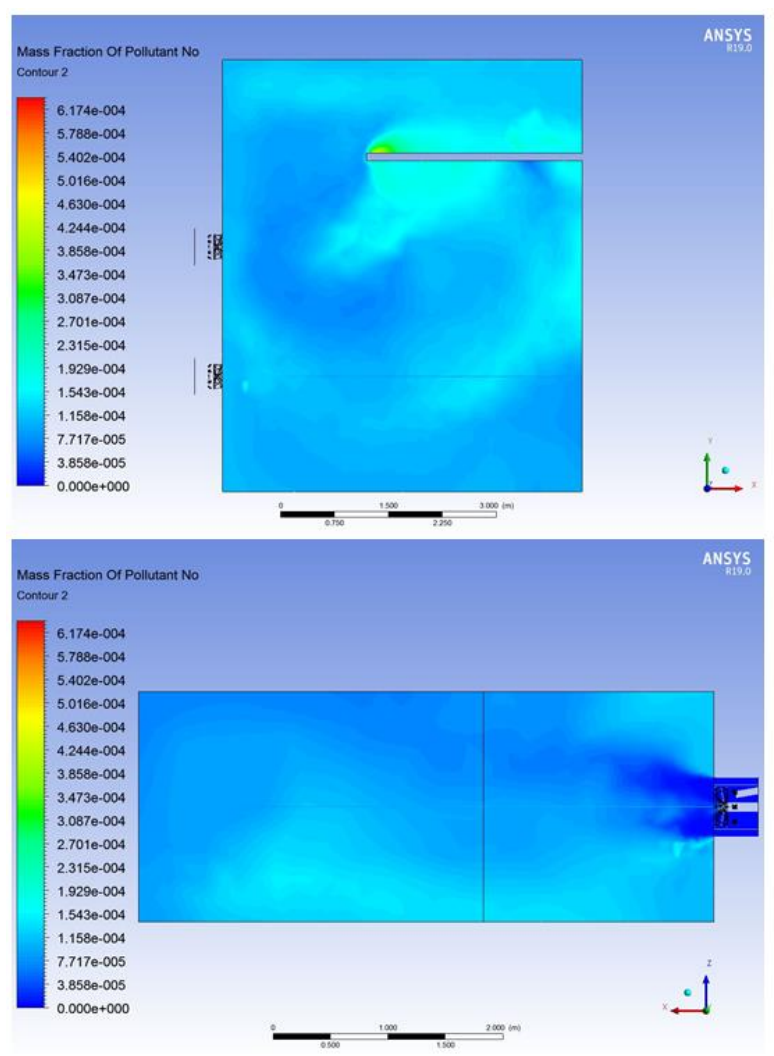

Figure 6. Simulation results. NOx Mass Fraction

Figure 6 represents mass fraction of the NO. Maximum concentration of the NOx in the boiler is $113 \mathrm{mg} / \mathrm{m}^{3}$. The average concentration inside the combustion chamber is $84 \mathrm{mg} / \mathrm{m}^{3}$, concentration at the exhauster is $82 \mathrm{mg} / \mathrm{m}^{3}$.

According to the simulation results NOx concentration at the exhauster of the boiler reduced by almost $40 \%$ to $82 \mathrm{mg} / \mathrm{m}^{3}$ while the power of the boiler decreased only by $5 \%$ to approximately $33.5 \mathrm{MW}$.

To validate the results of the simulation the real measurements were made according to the new combustion parameters. The results of the measurements are at the table 3.

Table 3. Measurement results

\begin{tabular}{cccccc}
\hline Time & $\begin{array}{c}\text { Power, } \\
\mathrm{MW}\end{array}$ & $\begin{array}{c}\mathrm{NOx} \\
{\left[\mathrm{mg} . / \mathrm{m}^{3}\right]}\end{array}$ & $\begin{array}{c}\mathrm{CO} \\
{\left[\mathrm{mg} . / \mathrm{m}^{3}\right]}\end{array}$ & $\begin{array}{c}\mathrm{CO}_{2} \\
{[\%]}\end{array}$ & $\begin{array}{c}\mathrm{O}_{2} \\
{[\%]}\end{array}$ \\
\hline $\begin{array}{c}9: 45- \\
\text { 10:15 }\end{array}$ & 33.5 & 80 & 1 & 3.45 & 3.34 \\
\hline $\begin{array}{c}15: 00- \\
15: 30\end{array}$ & 33.4 & 79 & 1 & 3.32 & 3.29 \\
\hline
\end{tabular}

According to the measurements results and difference between the simulation and confirmed assumptions and efficiency of the proposed methods. The different between the simulation and real measurement was approximately $1-2 \%$.

\section{CONCLUSIONS}

The theoretical and experiential knowledge which you can read above allow understanding and predicting the thermal NOx formation as well as the methods of their reduction.

Simulations also confirm the mechanism of the NOx formation according to the Arrhenius formulation in the thermal 
equipment with high thermal load of the combustion chamber. To decrease the NOx concentration in exhausted gases was proposed:

- Change the natural gas distribution between the burners - increase the power of the upper burner by $3 \%$ and decrease the power of the lower burner by $3 \%$

- Change the combustion air ratio at the lower burner the basic ratio was $70 \%$ of primary to $30 \%$ of secondary air, the new ration $65 \%$ of primary air to $35 \%$ of secondary air.

Implementation of these steps allowed reduce NOx concentration by almost $40 \%$ to $82 \mathrm{mg} / \mathrm{m}^{3}$ while the power of the boiler decreased only by $5 \%$ to approximately $33.5 \mathrm{MW}$.

\section{ACKNOWLEDGMENTS}

This work was supported by the Slovak Research and Development Agency under the contract No. APVV-16-0192

\section{REFERENCES}

[ANSYS 2019] ANSYS Fluent documentation for Fluent 2019.

[Deshpande 2017] Deshpande, A., Krishnaswamy, S. Ponnani, K., Corrigendum to "Experimental investigations on unmixed combustion for heat transfer applications" [Chem. Eng. Sci. 164 (2017) 122-132], Chemical Engineering Science, 2018, Vol. 192, pp. 1260. ISSN:0009-2509.

[Dobakova 2018] Dobakova, R., Brestovič, T., Jasminská, N. Determination of Heat Exchange on the Internal Side of Pipelines in District Heating Systems. Global Journal of Advanced Engineering Technologies and Sciences: GJAETS, 2018, Vol. 5, No. 11, pp. 10-14. ISSN 2349-0292

[Garre 2018] Garre, P., Susmitha, C. Numerical simulation of gas turbine blade cooling. In: IOP Conference Series: Materials Science and Engineering, Volume 455, Issue 1, 20 December 2018, 2nd International Conference on Advancements in Aeromechanical Materials for Manufacturing, ICAAMM 2018; Telangana; India; 13 July 2018.

[Jandacka 2015] Jandacka, J. et al. Optimization principle of operating parameters of heat exchanger by using CFD simulation. In: Proceedings of 10th International Conference on Experimental Fluid Mechanics, EFM 2015, November 2015, Code 121087, ISSN 2101-6275.

[Panda 2014] Panda, A., et. al. Progressive technology diagnostic and factors affecting to machinability. Applied Mechanics and Materials, 2014, vol. 616, pp. 183-190, ISSN 1660-9336. [Dzurnak 2015] Dzurňák R., et al. Simulation of the gaseous fuels burning by CFX software. In: Seminary on energy process, Košice, 2015.

[Krenicky 2010] Krenicky, T. The Monitoring of Technical Systems Operation Using Virtual Instrumentation. In: Strojarstvo extra. No. 5 (2010), pp. 25/1-25/2. ISSN 1335-2938. (in Slovak)

[Rimar 2013] Rimar, M., Skok, P. Thermodynamics, TUKE, FVT, 2013.

[Rimar 2014] Rimar, M., Fedak, M. Combustion processes. TUKE, Presov, 2014.

[Rimar 2016] Rimar, M., Fedak, M., Kulikov A., Šmeringai, P., TECHNOLOGY OF GASEOUS FUEL COMBUSTION RESPECT TO NOX FORMATION, Modern Machinery (MM) Science Journal, November 2016. DOI : 10.17973/MMSJ.2016_11_201665
[Saini 2018] Saini, G., Saini, R.P. Numerical Investigation of the Effect of Blade Profile of a Darrieus Hydrokinetic Turbine. In: 5th IEEE Uttar Pradesh Section International Conference on Electrical, Electronics and Computer Engineering, UPCON 2018, 31 December 2018, 5th IEEE Uttar Pradesh Section International Conference on Electrical, Electronics and Computer Engineering, UPCON 2018; Gorakhpur; India.

[Smeringai 2014] Šmeringai, P., Rimár, M. Process simulation in combustion plants with a few industrial burners. Management of Manufacturing Systems, 2014, pp. 116-119.

[Smeringai 2015] Šmeringai, P., et al. Optimization of combustion process with respect to the assessment of nitrogen oxides formation. Energy transformations in industry. Košice, pp. 190-194, 2015.

[Song 2018] Song, G., et al. Investigation on the mechanical properties and mechanical stabilities of pipewall hydrate deposition by modelling and numerical simulation. Chemical Engineering Science, 2018, Vol. 192, pp. 477-487.

[Tolias 2018] Tolias, I.C., Venetsanos, A.G. An improved CFD model for vented deflagration simulations - Analysis of a medium-scale hydrogen experiment. International Journal of Hydrogen Energy, 2018, Vol. 43, Issue 52, pp. 23568-23584, ISSN 0360-3199.

[Varga 2015] Varga, A., et al. The oxidant in the combustion process, 1st ed., Košice, 2015.

https://ansyshelp.ansys.com.

\section{CONTACTS}

Prof. Ing. Miroslav Rimar, CSc.

Ing. Marcel Fedak, PhD.

Ing. Andrii Kulikov PhD.

Technical University of Kosice

Faculty of Manufacturing Technologies with a seat in Presov

Department of Process Technique,

Sturova 31,080 01 Presov, Slovak Republic

tel.: +421-55-602-6341

e-mail: miroslav.rimar@tuke.sk,

e-mail: marcel.fedak@tuke.sk

e-mail: andrii.kulikov@tuke.sk 